\title{
The Specificity of Leadership Communication
}

Shiva Raj Pantha*

\begin{abstract}
This paper analyzes and discusses the link between leadership and communication. Drawing the leadership specific communication traits into discussion, the paper announces that leadership communication is different from followership communication. Among many, three particular discussion points have been taken into account viz. memorability of messages, the use of business stories and nonverbal signals. Organizational leaders resort to the higher memorability of their messages using the stories and the strengthening of the messages is made possible through the stronger gestures, postures, eye movements and very congruent voices. Thus, this paper contends that leadership employs the communications patterns that are different from other executive positions in an organizational setting.
\end{abstract}

Key Words: Analogy, Business Stories, Eye Movement, Gestures, Memorability, Metaphors, Posture, Voice

\footnotetext{
${ }^{\star}$ Assistant Professor, Tribhuvan Unversity, Kathmandu, Nepal Email: pantashivaraj@gmail.com
} 


\section{Introduction}

Most of us agree that effective communication skills are at the center of the professional life. No matter what position we hold in a workplace, powerful communication skills are an asset. When it comes to the importance of the communication capabilities of an organization leader, we are more vigilant. Courtland Bovee et al put, “... the higher you rise in your organization, the more important communication becomes. Top managers spend as much as $85 \%$ of their time communicating with others" (2011, p. 5). A leader needs to communicate the plans, visions and other daily activity inventories to the stakeholders. If the expected message fails to reach the stakeholders, a situation of turmoil begins. When the message delivery of the low executive fails, the cost is not that high. However, if the message delivery of the chief executive officer fails, the execution is disturbed and the cost is considerably high. When the leaders communicate, they follow a certain trail. Said that, their communication pattern can be modelled for turning oneself to a leading role. Perhaps raising oneself to a leadership role requires various capacities, communication capability is one of them. If the communication needs of an organization are not met, the leadership role can be called into question.

This paper intends to analyze the powerful communication traits of a leader. In other words, the crux of this paper is to explore the link between effective communication and successful leadership. This paper, thus has an attempt to answer the questions- Do leaders have unique communication strategies? Which strategies are more pivotal for their successful leadership? In so doing, the paper will limit itself from the discussion of various types of leadership styles. Also, the economy of space issue in this paper will call for the limitation of the discussion of the wider area of communication studies. Chiefly thus, this paper brings forth three aspects of communication traits for the effective leadership execution, namely, the memorability and repeatability of the messages, the nonverbal aspects for the direction, followership and implementation plus the narrative intelligence.

\section{Business Stories and Leadership Perception}

The storytelling skill that we learn from our parents and grandparents especially in the form of bedtime stories do have precious implications in the rendering of the leadership role. Greatly misunderstood as the genre of literature class, storytelling skill or the narrative intelligence has been one of the powerful leadership communication skills. Although the courses like literature for leadership have been the recent courses for executive education, the focus is less than required in the Nepalese business education. Since this paper has the scope to discuss the link between leadership and communication, the importance of literature for leadership can be a topic for a separate research paper. The point is: the art of storytelling is not only the domain of literature class, rather it is a powerful skill required for the leadership delivery. 
There has been a large amount of research conducted in the area of the link between leadership and the narrative intelligence. Stephen Denning finds one powerful idea:

One study compared the effectiveness of four different methods to persuade a group of MBA students of an unlikely hypothesis, namely that a company really practiced a policy of avoiding layoffs. In one method, there was just a story. In the second, the researchers provided statistical data. In the third, they used statistical data and a story. In the fourth, they offered a policy statement made by a senior company executive. The most effective method of all turned out to be the first alternative, presenting a story alone. (2005, p.22)

As Denning, out of the four techniques of delivering the ideas to the audience, the storytelling has been the most preferred one and the most effective one. People mistake the power of facts and numbers. In the surface, they seem to have the power, in the deeper sense, they do not. What matters is the story that can shape the people' imagination and the larger reception rate of the message. Human beings are not the dry beings to ask for bare facts, they do have imagination and the narrative quest, this is quenched by the business stories that a leader chooses to serve with. Because the stories might be the most powerful routes to the people's mind, using stories can truly benefit the leaders. The stories can be used as the catalyst for the action. The stories are the springboards for the imagination. Human beings' fundamentally story-loving nature has been foreshadowed. Inwardly, the instinct is freshly surviving. Jonathan Gotschall brings forth this notion:

Human life is so bound up in stories we are thoroughly desensitized to their weird and withy power. So to start this journey, we need to pry back the veneer of familiarity that keeps us from noticing strangeness of story. All you have to do is open up a story book, almost any storybook and pay attention to what it does to you. (2012,p.1)

Our involvement in the other worldly affairs has made us forget the basic instinct we are born with. To connect, in the business education recently, the use of case studies for the impactful teaching has been the revival strategy for the shadowing of the narrative intelligence in the people. We are desensitized by the so-called scientific inventions, facts and other numerical details. Human beings do not love those abstract and dull numbers. What they need is the story that contains the human dimensions.

The hard facts and boring bullet points are less powerful when the leaders are required to connect, inspire and influence. The stories and the imaginative dimensions of the stories can conduct such a task easily. The good business cases wish to establish a belief or the corporate values of a company through the stories and not through the dry and abstract numbers. The leaders need to take the shelter in the stories because human beings have the 
tendency to share the most complex ideas through the stories. The tradition has it that the stories were passed down to the generations because the human values could not be passed down directly. The fables, the classics and even the religious scriptures are handed down to us in the form of stories in that they shape our mind easily, they help us connect the values required for the lives. They are used for communicating and transmitting the complex and powerful ideas. Stories can be used by the leaders for defining their personality, boosting confidence and displaying integrity. Also, the stories provide the opportunities for the leaders to reflect on their strategies to deal with the difficult situations they come across. Also, the leaders use stories to inculcate positive corporate values and norms in the hearts and minds of the audience. Janis Forman observes:

The art of storytelling helps leaders- and aspiring leaders- put together compelling and memorable cases for their recommendations, embedding significant details and data into their stories to substantiate the future they envision for their organization. (2013,p.XI)

Forman elucidates why stories become cardinal in the execution of the successful leadership in any organizational settings.

\section{Memorability of Messages For Successful Leadership}

In a day, the employees and stakeholders in the organizational setting face hundreds of verbal messages. Not all of the messages do have the equal power to impact upon the performance of the stakeholders. And thus, most of the messages have relatively shorter lives. The efficacy of the leadership is indicated by the regular use of the memorable messages. Black (2007) claims that ...... certain communication traits have been observed to correlate with successful leadership... the ability to enhance memorability of messages, such as "If you are not helping, you are hindering .

The leaders require various skills. Among them, the important skill is to be able to maximize the effects of their verbal messages. Be it the message regarding the vision of the organization or the negative news related to the employees, the framing of the message in the audience friendly manner with the inspirational touch and the central aspect of memorability enhances the execution of the message. The rhetorical aspect of the message is important in this regard. It is not to say that the nature of content does not matter. It matters the most. However, the framing of the message in the respectful manner along with the acceptability and memorability adds the leadership with the turbocharged efficacy. When the messages are influential, their effects are far-reaching. Jay A Conger elucidates:

From the recent attention that the subject of leadership has received, we know that one critical role of effective leaders is to be skillful craftsmen of their organization's mission. We also know that of equal importance is the ability to communicate their missions in ways 
that generate great intrinsic appeal.' A leader must not only be able to detect opportunities in the environment but to describe them in ways that maximize their significance. This ability to describe is captured by the simple story of two stone masons who, while working on the same project, were asked what they were doing. The first replied: "I am cutting stone;" the second: "I am building a great cathedral." The latter was able to describe his work in a more far-reaching and meaningful way. Work for him had a higher purpose. Leadership today must embody this same ability-the capacity to articulate an organization's mission and communicate it in ways that inspire. Sadly however, this capacity depends upon skills that have been largely neglected by the business world. (1991,p.31)

Conger highlights the need of inspiring the stakeholders through the framing of the messages in the memorable ways. For him, the part to lament is that the business firms are neglecting this aspect of the communication. Even in Nepalese contexts, we have overlooked this aspect in the leadership. The aspects like the hard skills and financial skills are focused. The delicate balance among these aspects do enhance the organizational images. When Steve Job utters," The only way to do a great work is to love what you do." $\mathrm{He}$ is not dictating. He is influencing, inspiring and motivating. Why are some messages memorable and others not? Dictating and reaching a goal has been the thing of the past. It is only through the motivation and inspiration that the leaders can bring the desired changes in an organization. As it has been argued elsewhere that the communication efforts matter a lot in the act of moving the stakeholders to the actions, the quality of the messages that the leader produces must be rigorously scrutinized or it can have the adverse effects. The messages of the leaders need to be rarely unfamiliar and unrecognized because leading means removing the heavy responsibility for thinking, there can be varous ways to create the messages memorable.

Two important techniques for such a task are using the metaphors and the use of anlaogies. Highlighting the need of the use of the metaphors and analogies in the leadership execution. Jay A. Conger further clarifies:

...studies from social psychology explain why these rhetorical devices are a more persuasive and effective means of communicating ideas.' It has been found that people treat statistical summaries as if they were uninformative. This type of information appears to lack impact because of its abstract, colorless nature. In contrast, brief, face-to-face comments have been found to have a substantial impact on decision-making. It might be concluded that information is used in proportion to its "vividness." (1991,p.31).

The use of analogies and the metaphors help the memorability of the messages. For instance, when a company is on the crisis moments, the leader might utter statements like- the sun does not set for longer, the next morning with a brighter sun will appear soon 
after the night. Here, the use of metaphor- sun as the success can help the stakeholders get motivated.

Similarly, the analogy, a bit different from the use of metaphor especially in the form of the larger chunks of the representations can be impactful. For instance, a company's crisis period can be compared to a mother's pregnancy and gestation period in which a mother suffers for a positive result. The leader can use this analogy for uplifting the stakeholders' morale and can direct their focus to the desired result. Jay A. Conger adds:

Why are metaphors and analogies so powerful in communicating ideas and goals? And are they more powerful than arguments supported by logic and statistics? These are important questions since corporations and MBA programs encourage the latter carefully planned managerial presentations supported with a wealth of statistical information. And while such presentations are critical to effective decision-making, this style has become so engrained that managers use a similar format in speeches, in pep talks to their organizations, and in discussions with customers and analysts. Leaders, especially the more inspirational ones, appear to more often use such forums to "orate" and to convey their messages through metaphors, analogies.... (1991,p.39)

While the use of the metaphors and analogies can be asked for the oratory, the serious direction and the execution of the messages too can be done through the use of the metaphors and analogies.

\section{Nonverbal Skills for Leadership Execution}

The respectful hand movements, governing gaze, tonality and the posture can be other factors that the leadership communication is deeply related. The perception of the leadership is affected by these four aspects. Kit Field et.al discuss, "A more nervous or submissive approach would involve nervous hand movements, avoiding eye contact, hesitating and speaking quietly. (2000,p.224)" Apart from the capability of the business storytelling and the memorability of the messages, the effective use of these nonverbal skills are the inseparable traits that a leader needs to possess. In fact, they can enhance the success or damage the image of the leader, Carol Kinsey and Goman Jossey amplify, "Nonverbal signals can literally make or break a leader's success"( 2011, p. 4). Their idea has a lot of truth because the nonverbal signals can strengthen or weaken the verbal messages. For instance, if the employees have come to the leader's chamber for the rise of pay-scale and the leader promises that the rise can be made and he/she is positive about it. However, if he/she engages herself/ himself in the computer/ laptop, and has the fugitive smiles on the faces, this activity does weaken his message that he/she is sincere about the rise of the pay-scale. His verbal messages are contradicted by his nonverbal involvements. This is quite unprofessional and the employees will take him negatively. Even if the leader has to say that the pay-scale cannot be improved, he can remain neutral and serious with 
his/her nonverbal signals. He/she can be sincere and provide sufficient time explaining the things. This instance is a case that shows how the verbal messages are amplified or contradicted through the nonverbal messages.

\section{Voice}

We should be able to adapt the voice to fit the role. Voice workers like singers and teachers know the value of the voice. They know the effect of their voice, the loudness, the softness among others. The voice can determine the role. Conversely, the voice that is low can be the symbol of the submission. It does not mean that the voice that is loud is required. The voice that is demonstrates confidence, authority and dedication can be characterized as the voice of leadership. In fact, it is the voice that punctuates the faith of the team and attracts the audience. What is important about the voices is that neither the high pitched voice nor the low pitched voice can gain the respect and popularity. What matters is the ability to stretch the voice to both limits. The manipulation of the voice as and when required can gain the respect. The leader with the capability to stretch the voice is the suitable one to lead longer.

\section{Hand Movements/ Gesture}

The feeble gesture cannot be the tool for a leader. The firm hand movement coordinated by other body movements and the facial expressions can help establish the leader's trustworthy image. The leader needs to take caution about the appropriate hand movements, the pointing of the fingers, the claps and other activities with the hands. Further, the strong and the firm movements that are closely linked with the verbal messages can help establish the leader's enhanced image in the wider areas.

\section{Eye Signals}

As the business experts observe, the eyes are the windows to the souls, there are no truer words. The emotional aspects of the leader are understood through the eyes. The caring eyes, the loving eyes, the furious eyes and frustrated eyes. Whatever, the manipulation of the eyes for the intended purpose should the priority of the leader because the eyes speak a lot. If they contradict the messages, the image will be damaged and the execution of the leadership becomes feeble. The improvement of the eye signals can be done through some eye exercises.

\section{Posture}

The emotions are created by motions. When the leaders do have strong postures while sitting or standing or walking, they signal a positive image and earn the credibility that the leader is highly committed to the assigned or is devoted to the visions made. If the leader walks briskly and the leans forward while sitting, this signals the negative message to the audience. This simple looking signal has incalculable effect. Often times, the minor things have the power of the major things. 
Hence, the nonverbal aspects particularly, voice, eye movements, gesture and posture of the leader need to be taken into consideration by the leaders in that they are the signals that make or break the message of the leader. They are the final doors through which the messages pass to the stakeholders and the perception of the leadership is affected.

\section{Final Remarks}

Thus, this paper argues for the leadership specific communication traits that are different from other traits. Particularly speaking, leadership perception and execution are determined by the memorability of the messages, the use of inspiring business stories and the powerful nonverbal signals. As leadership is about the direction of the organizational path to an orbit, the communication efforts need to be steered in the set direction. To be more precise, the leadership communication necessitates the difference from other sets of communication.

\section{References}

Bovee,C., Thill, V. J., \& Chatarjee, A. (2011).Business communication today. Delhi, India:Peaarson,

Charteis-Black,J.(2007).The communication of leadership: The design of leadership style. Oxon, England: Routledge.

Conger,J.A. Inspiring Others: The language of leadership.JSTOR,5(1),31-45. https://www. jstor.org/stable/4164992.

Denning, S. (2005).The leader's guide to storytelling: Mastering the art and discipline of business narrative. San Francisco,U.S.A.: Jossey Bass.

Field, K., Holden, P., \& Lawlor,H.(2002).Effective subject leadership.London,U.K. Routledge.

Forman, J. (2013).Storytelling in business .Stanford, U.S.A.:Stanford University Press.

Gotschall, J. (2012).The storytelling animal: how stories make us human. Boston, U.S.A.Houghton Mifflin Harcourt.

Kinsey, C.\& Jossey, G. (2011).The silent language of leaders.San Francisco,U.S.A.:Bass. 